\title{
EX VIVO INTERFERON-GAMMA IMMUNE RESPONSE TO THROMBOSPONDIN-RELATED ADHESIVE PROTEIN IN COASTAL KENYANS: LONGEVITY AND RISK OF PLASMODIUM FALCIPARUM INFECTION
}

\author{
KATIE L. FLANAGAN, TABITHA MWANGI, MAGDALENA PLEBANSKI, KENNEDY ODHIAMBO, AMANDA ROSS, \\ ERIC SHEU, MOSES KORTOK, BRETT LOWE, KEVIN MARSH, AND ADRIAN V. S. HILL \\ Weatherall Institute of Molecular Medicine, University of Oxford, John Radcliffe Hospital, Headington, Oxford, United Kingdom; \\ KEMRI-Centre for Geographic Medicine-Coast, PO Box 230, Kilifi, Kenya
}

\begin{abstract}
Thrombospondin-related adhesive protein (TRAP) of Plasmodium falciparum is currently being tested in human vaccine studies. However, its natural reactivity in the field remains poorly characterized. More than $40 \%$ of 217 Kenyan donors responded in an ex vivo interferon- $\gamma$ (IFN- $\gamma$ ) enzyme-linked immunospot (ELISPOT) assay to at least one of 1420 mer peptides spanning $42 \%$ of the antigen. Reactivity was comparable from early childhood ( $>1$ year of age) to old age, and the maximal precursor frequency of TRAP-specific cells to all 14 peptides was 1 in 4,000. Prospective follow-up for one year indicated that these low-level ex vivo responses to TRAP did not protect against the subsequent development of malaria. Retesting of selected donors after one year showed a complete change in the reactivity pattern, suggesting that malaria-specific ex vivo IFN- $\gamma$ ELISPOT assay responses are short lived in naturally exposed donors, even to conserved epitopes. This study provides important information regarding natural reactivity to a key malaria antigen.
\end{abstract}

\section{INTRODUCTION}

The development of an effective vaccine may provide the most effective method of reducing the worldwide burden of malaria. Understanding the mechanisms of natural protective immunity, and identifying target antigens and epitopes, are important for effective vaccine development. Controversy remains over whether protective effector mechanisms and antigens identified in animal studies, or vaccine induced protective responses, can predict protective mechanisms induced by natural malaria infection. Despite strong laboratory evidence that pre-erythrocytic protection is T cell mediated, few field studies have directly looked for correlates of protection with $\mathrm{T}$ cell responses in malaria exposed populations. Those to date have assessed lymphoproliferative responses to malaria derived peptides and proteins and cytokine release by an enzyme-linked immunosorbent assay (ELISA), ${ }^{1-6}$ yet none have convincingly demonstrated a protective $\mathrm{T}$ cell response.

Numerous studies implicate the Th1 type cytokine interferon- $\gamma($ IFN- $\gamma)$ as the effector mechanism by which $\mathrm{T}$ cells mediate protection at the pre-erythrocytic stage of malaria infection. ${ }^{7-9}$ The enzyme-linked immunospot (ELISPOT) assay detects individual $\mathrm{T}$ cells present in peripheral blood that release IFN- $\gamma$ within 16 hours of stimulation with specific antigen. It thus provides an immediate reflection of the precursor frequencies of peptide-specific IFN- $\gamma$-producing cells in peripheral blood without prolonged selective cultures, such as the ones necessary for limiting dilution analysis. The ELISPOT assay is simple to perform and provides a highly sensitive method for assessing cytokine production in malaria exposed populations. ${ }^{10-13}$ In animal studies of pre-erythrocytic vaccines IFN- $\gamma$ ELISPOT assay responses to pre-erythrocytic antigens of more than a few hundred per million splenocytes are strongly associated with protection. ${ }^{14,15}$ The human RTS,S vaccine, which is based on the pre-erythrocytic antigen circumsporozoite (CS) protein, protects malarianaive donors against homologous challenge. ${ }^{16}$ Those protected had detectable but modest levels of CS protein-specific IFN- $\gamma$-producing $\mathrm{CD}^{+} \mathrm{T}$ cells by ELISPOT assay and high levels of antibody to CS. However, it is not known if IFN$\gamma$-producing $\mathrm{T}$ cells detected by ELISPOT assay in vacci- nated or naturally exposed humans directly mediate protection.

A favored pre-erythrocytic vaccine candidate antigen is thrombospondin-related adhesive protein (TRAP), ${ }^{17}$ also referred to as SSP2. ${ }^{18}$ This protein is located in the secretory organelles of sporozoites and is released onto the sporozoite surface upon contact with target cells. ${ }^{19}$ It is responsible for the gliding motility of sporozoites, ${ }^{20}$ and is involved in hepatocyte invasion. ${ }^{21}$ Adoptive transfer experiments have demonstrated protective TRAP-specific $\mathrm{CD}^{+} \mathrm{T}$ cells in mice. ${ }^{22}$ Immunization with a mixture of transfected cells expressing Plasmodium yoelii TRAP/SSP2 and CS protected mice against this parasite. ${ }^{23}$ A DNA/modified virus Ankara (MVA) prime-boost regimen using the $P$. berghei TRAP antigen gave very substantial protection in mice. ${ }^{14}$ Immunization with a linear synthetic peptide containing four copies of a $P$. yoelii TRAP/SSP2 sequence induced $\mathrm{CD} 4^{+} \mathrm{T}$ cell and IFN- $\gamma$-dependent sterile protective immunity against malaria challenge in AJ mice, but not BALB/c or C57BL/6 mice. ${ }^{24}$ TRAP-specific $\mathrm{CD}^{+} \mathrm{T}$ cells have been demonstrated in sporozoite immunized and naturally exposed humans, ${ }^{25-27}$ and TRAP-specific $\mathrm{CD} 4^{+} \mathrm{T}$ cell reactivity has been detected in naturally exposed Gambians. ${ }^{10}$ Two field studies support a protective role for humeral responses to TRAP in naturally exposed humans, ${ }^{28,29}$ but no human studies have assessed protective TRAP-specific $\mathrm{CD} 4^{+}$or $\mathrm{CD}^{+} \mathrm{T}$ cells.

The present study was undertaken to determine whether naturally exposed Kenyans have $P$. falciparum TRAP-specific IFN- $\gamma$-producing $\mathrm{T}$ cell responses, and compare ELISPOT assay reactivity between adults and children in terms of responder numbers, precursor frequency levels, and the repertoire of peptide responses. Peptides spanning 240 amino acid residues of TRAP strain NF54 (42\% of the antigen) were tested in overnight ELISPOT assays for their ability to induce IFN- $\gamma$ production in over 200 Kenyan volunteers between 1 month and 81 years of age. These donors were then followed up weekly for one year for episodes of clinical malaria and the protective value of the ELISPOT assay responses was analyzed. Selected donors were retested after one year in identical assays to determine the long-term stability of these re- 
sponses. This data provides a comprehensive picture of natural $\mathrm{T}$ cell reactivity to TRAP in a naturally exposed population.

\section{MATERIALS AND METHODS}

Study site and volunteers. Two hundred seventeen donors between 1 month and 81 years of age (57\% females, $43 \%$ males) were recruited from Ngerenya in the northern part of Kilifi District in coastal Kenya. Informed consent was obtained from all donors or the parent/guardian of children. Five milliliters venous blood was collected from each donor at Kilifi District Hospital throughout the first two weeks of September, at the end of the peak malaria transmission period (June to August). ${ }^{30}$ Ngerenya district is an area of moderate malaria transmission with an entomologic inoculation rate of 10 (range $=3-15$ ) infectious bites per person/year (Mbogo C, unpublished data). Fifteen malaria-naive adult employees at the John Radcliffe Hospital in Oxford were also recruited into the study as controls. Ethical approval for this study was obtained from the Kenyan Ethical Committee, and is published with the permission of the director of the Kenya Medical Research Institute.

Preparation of peripheral blood mononuclear cells (PBMCs). Peripheral blood mononuclear cells were isolated by density gradient centrifugation on Lymphoprep (Nycomed, Oslo, Norway), collected from the interface, washed three times in RPMI 1640 medium, and resuspended in complete RN5 medium (RPMI 1640 medium supplemented with $5 \%$ heat-inactivated human $\mathrm{AB}$ serum, $2 \mathrm{mM}$ glutamine, $100 \mu \mathrm{g} / \mathrm{ml}$ of streptomycin, and $100 \mathrm{units} / \mathrm{ml}$ of penicillin) for use in cellular assays. The $\mathrm{CD}^{+}$and $\mathrm{CD}^{+} \mathrm{T}$ cell depletions were performed using anti-human CD4 and CD8 magnetic dynabeads, respectively, (Dynal, Bromborough, United Kingdom) according to the manufacturer's instructions. The protocol reliably depleted $>95 \%$ of the $\mathrm{CD}^{+}$or $\mathrm{CD}^{+}$cells as confirmed by fluorescent-activated cell sorting analysis (FACScan analysis). Cells were recounted and resuspended in RN5 medium for use in cellular assays.

Peptides. A pilot study of 65 Kenyan adults was performed to select the peptides for the trial. A panel of 53 overlapping 20mer peptides spanning the length of $P$. falciparum TRAP were tested in ex vivo IFN- $\gamma$ ELISPOT assays in the 65 do- nors. Fourteen TRAP 20mer peptides (denoted tps) from strain NF54 were selected for the study. Those selected included all those that induced reactivity in $\geq 9 \%$ of the 65 donors plus a few of particular interest, such as one highly conserved (tp23), one highly polymorphic (tp43), or one containing a domain of proposed functional significance (tp30) (Table 1). Peptides were reconstituted in phosphate-buffered saline (PBS) (Sigma, Dorset, United Kingdom) and PBS alone was used as a negative control. Overlapping peptides tp4, tp5, and tp6 were pooled and tested as one group, as were peptides tp30 with tp31 and tp37 with tp38. This gave $10 P$. falciparum TRAP conditions for testing in the donors (Table $1)$. None of the selected peptides induced IFN- $\gamma$ ELISPOT assay responses in 15 naive control donors tested under identical conditions in Oxford. Two peptides contained TRAP sequences conserved across all known antigenic variants worldwide (tp2 and tp23), and six peptides were conserved across all known African variants (tp2, tp6, tp14, tp23, tp40, and tp51) (Table 1). The $\mathrm{CD}^{+}$and $\mathrm{CD} 8^{+}$cell depletion studies suggested that IFN- $\gamma$ ELISPOT assay responses to seven of the 14 TRAP peptides elicited $\mathrm{CD}^{+} \mathrm{T}$ cell responses, and two were $\mathrm{CD}^{+}$or $\mathrm{CD}^{+} \mathrm{T}$ cell mediated even in the same donor (summarized in Table 1). All peptides were used at a final concentration of $25 \mu \mathrm{g} / \mathrm{mL}$ following preliminary titration assays from 1 to $50 \mu \mathrm{g} / \mathrm{mL}$. Purified protein derivative (PPD) of Mycobacterium tuberculosis was used as a positive control at a concentration of $25 \mu \mathrm{g} / \mathrm{mL}$. All 217 donors were tested against the 10 TRAP peptide conditions and PPD, except for 68 donors who were not tested for reactivity to tp3031. Phytohemagglutinin (PHA) was used as an additional control at a concentration of $10 \mu \mathrm{g} / \mathrm{mL}$ in selected assays.

Ex vivo IFN- $\boldsymbol{\gamma}$ ELISPOT assay. The IFN- $\gamma$ ELISPOT assays were carried out using 96-well MAIP ELISPOT plates (Millipore, Watford, United Kingdom) and human IFN- $\gamma$ ELISPOT kits (Mabtech, Nacka, Sweden) as described in detail elsewhere. ${ }^{11}$ Briefly, plates were coated with $15 \mu \mathrm{g} / \mathrm{mL}$ of monoclonal antibody to human IFN- $\gamma$ (1-D1K; Mabtech), washed, and blocked with R10 medium (RPMI 1640 medium with $10 \%$ fetal calf serum). The PBMCs, resuspended at a concentration of $4 \times 10^{6} / \mathrm{ml}$ in RN5 medium, were applied at a concentration of $100 \mu \mathrm{L} /$ well $\left(4 \times 10^{5}\right.$ cells/well $)$ and tested against the 10 TRAP peptide conditions, with PPD and PBS used as the positive and negative controls, respectively.

TABLE 1

The 14 thrombospondin-related adhesive protein peptides selected for the study*

\begin{tabular}{|c|c|c|c|c|c|c|}
\hline Epitope & aa & Sequence & Frequency & $\mathrm{CD} 4 / \mathrm{CD} 8$ & Worldwide & Africa \\
\hline $\operatorname{tp} 2$ & $11-30$ & VIVFLIFFDLFLVNGRDVQN & $9 \%$ & ND & Conserved & Conserved \\
\hline tp4 & $31-50$ & NIVDEIKYREEVCNDEVDLY & $12 \%$ & ND & Variant & Variant \\
\hline tp5 & $41-60$ & EVCNDEVDLYLLMDCSGSIR & $9 \%$ & CD4 and CD8 & Variant & Variant \\
\hline tp6 & $51-70$ & LLMDCSGSIRRHNWVNHAVP & $12 \%$ & CD4 and CD8 & Variant & Conserved \\
\hline tp14 & $131-150$ & TNLTDALLQVRKHLNDRINR & $9 \%$ & CD4 & Variant & Conserved \\
\hline tp23 & $221-240$ & ENVKNVIGPFMKAVCVEVEK & $7 \%$ & CD4 & Conserved & Conserved \\
\hline tp30 & $291-310$ & EPLDVPDEPEDDQPRPRGDN & $7 \%$ & ND & Variant & Variant \\
\hline tp31 & $301-320$ & DDQPRPRGDNFA VEKPNENI & $9 \%$ & CD4 & Variant & Variant \\
\hline tp37 & $361-380$ & PPNPPNPPNPDIPEQEPNIP & $9 \%$ & ND & Variant & Variant \\
\hline tp38 & $371-390$ & DIPEQEPNIPEDSEKEVPSD & $9 \%$ & CD4 & Variant & Variant \\
\hline tp40 & $391-410$ & VPKNPEDDREENFDIPKKPE & $9 \%$ & ND & Variant & Conserved \\
\hline tp43 & $421-440$ & NDKSDRYIPYSPLSPKVLDN & $5 \%$ & CD4 & Variant & Variant \\
\hline tp47 & $461-480$ & SEDRETRPHGRNNENRSYNR & $9 \%$ & CD4 & Variant & Variant \\
\hline tp51 & $526-545$ & AGLAYKFVVPGAATPYAGEP & $14 \%$ & CD4 & Variant & Conserved \\
\hline
\end{tabular}


The plates were incubated for 16 hours at $37^{\circ} \mathrm{C}$ in an atmosphere of $5 \% \mathrm{CO}_{2}$, washed, and a second biotinylated monoclonal antibody to IFN- $\gamma$ (7-B6-1-Biotin; Mabtech) was applied at a concentration of $1 \mu \mathrm{g} / \mathrm{mL}$, followed by $1 \mu \mathrm{g} / \mathrm{mL}$ of streptavidin-alkaline phosphatase (Mabtech). Plates were then washed and developed with alkaline phosphatase conjugate substrate kit (Bio-Rad Laboratories, Hercules, CA). The reaction was stopped after 10-20 minutes by flicking off the liquid and running the plate under tap water.

Each IFN- $\gamma$-producing cell leaves a single spot or footprint in the ELISPOT assay well. Wells were scored visually, using a dissection microscope, for the number of purple spots or spot-forming units (SFUs) per well. The results were expressed as SFUs $/ 10^{6}$ PBMCs. The number of responder cells in the single test well was compared with the background negative well. A statistical significance table was used that assumes a Poisson distribution for the number of spots in each well, and gives a $P$ value for the likelihood that the result is a true positive rather than a chance event above background. All responses with a $P \leq 0.05$ were recorded as positive.

Follow-up for malaria. Active follow-up was performed weekly by a team of field workers. Each household was visited, and the temperature of each trial participant was recorded. A history was taken regarding fever and any other clinical symptoms over the preceding week. Those with a history of fever, or a temperature $>37.5^{\circ} \mathrm{C}$ on the day of the visit, were referred to the clinic and had duplicate finger prick blood smears prepared (thick and thin films stained with Giemsa). Patients presenting with fever to the outpatient clinic who were parasitemic on the blood film were also included in the analysis (passive follow-up). Parasite counts were scored as parasites/microliter of blood. All data was double-entered into a computer database and verified using Fox-pro version 6.0 (Microsoft, Bellevue, WA).

Statistical analyses. The proportion of responders among adults ( $\geq 15$ years old) and children (0-14 years old) were compared using a Fisher's exact test, and the magnitude of responses was compared using Student's $t$-test. The endpoints of the analysis for protection were defined a priori. Analysis was performed for delay in time to the first parasitemia, and number of donors with episodes of fever and parasitemia over two-month and six-month periods following the crosssectional ELISPOT assay testing. Since many people living in malaria-endemic regions have asymptomatic parasitemias, a second analysis was performed using a cut-off value of
$>10,000$ parasites $/ \mu \mathrm{L}$, which was more likely to detect clinically relevant episodes of parasitemia. Fisher's exact tests were used to compare those donors who had TRAP peptide specific responses with those who did not. Two sample $t$-tests were used to compare the SFU values for all 10 TRAP peptide conditions added together (total SFU) for those donors who subsequently did or did not have an episode. KaplanMeier estimates of the proportion of donors who had had at least one episode were plotted against time after the crosssectional analysis of TRAP ELISPOT assay responses. Logrank tests were used to compare survival experience for those donors with particular TRAP $\mathrm{T}$ cell epitope responses to those without these responses.

The relationship between total SFUs and time to first parasitemia appeared to be non-linear; thus, total SFU values were divided into four categories $(<0,0-49,50-99$, and $\geq 100$ ), rather than assessed as a continuous variable. Cox's proportional hazards were used to analyze the effect of total SFUs on time to first episode of malaria. This assumes that the effect of total SFU category remains constant over time.

\section{RESULTS}

Interferon- $\boldsymbol{\gamma}$ ELISPOT assay reactivity to TRAP in coastal Kenyans. Forty-two percent (91 of 217) of the donors responded to one or more of the 10 TRAP peptide conditions (14 peptides) (Table 2). This was higher than that observed in a previous Gambian study where $17 \%$ ( 8 of 48 ) of the donors responded to the same 14 peptides, and $32 \%$ of donors responded to 53 overlapping peptides spanning the entire length of the TRAP antigen. ${ }^{10}$ Reactivity to nine of the 14 peptides was first described in our study in west Africa, ${ }^{10}$ whereas the remaining five $(\mathrm{tp} 2, \mathrm{tp} 30, \mathrm{tp} 31, \mathrm{tp} 37$, and $\mathrm{tp} 51)$ are novel epitopes to which reactivity has never been reported. Magnetic bead depletion studies for 12 responder donors suggested that seven of the 14 peptides (tp14, tp23, tp31, tp38, tp43, tp47, and tp51) elicited $\mathrm{CD}^{+} \mathrm{T}$ cell responses by ELISPOT, and two (tp5 and tp6) were either $\mathrm{CD} 4^{+}$or $\mathrm{CD} 8^{+}$ $\mathrm{T}$ cell mediated (Table 1). Peptides tp 5 and tp6 both contain the known $\mathrm{CD}^{+} \mathrm{T}$ cell epitope tr29 (amino acids 51-59, LLMDCSGSI). ${ }^{25}$ and therefore $\mathrm{CD}^{+} \mathrm{T}$ cell reactivity was probably to this epitope. Almost half $(47.9 \%, 104$ of 217$)$ of the donors were parasitemic at the time of sampling. A significantly lower number of parasitemic individuals had a

TABLE 2

Frequency of responders to each of the 10 thrombospondin-related adhesive protein conditions by age group for the 217 donors*

\begin{tabular}{|c|c|c|c|c|c|c|c|c|c|c|c|c|c|}
\hline $\begin{array}{c}\begin{array}{c}\text { Age } \\
\text { (years) }\end{array} \\
\end{array}$ & $\mathrm{n}$ & tp2 & tp4-6 & tp14 & tp23 & tp30/1 & tp37/8 & tp 40 & tp43 & tp47 & tp51 & PPD & $\begin{array}{c}\text { Total } \\
\text { frequency }\end{array}$ \\
\hline \multirow[t]{2}{*}{$0-3$} & 47 & 2 & 6 & 1 & 4 & 4 & 2 & 1 & 2 & 2 & 4 & 15 & 20 \\
\hline & & $4.3 \%$ & $13.0 \%$ & $2.2 \%$ & $8.5 \%$ & $12.9 \%$ & $4.4 \%$ & $2.1 \%$ & $4.4 \%$ & $4.4 \%$ & $12.1 \%$ & $32.6 \%$ & $42.6 \%$ \\
\hline \multirow[t]{2}{*}{$4-6$} & 46 & 3 & 7 & 5 & 5 & 2 & 6 & 2 & 2 & 3 & 4 & 25 & 20 \\
\hline & & $6.5 \%$ & $15.2 \%$ & $10.9 \%$ & $10.9 \%$ & $7.1 \%$ & $13.0 \%$ & $4.4 \%$ & $4.4 \%$ & $6.5 \%$ & $8.7 \%$ & $54.3 \%$ & $43.5 \%$ \\
\hline \multirow[t]{2}{*}{$7-9$} & 49 & 3 & 5 & 1 & 3 & 1 & 1 & 1 & 3 & 1 & 2 & 23 & 16 \\
\hline & & $6.1 \%$ & $10.2 \%$ & $1.9 \%$ & $6.1 \%$ & $3.3 \%$ & $1.9 \%$ & $1.9 \%$ & $6.1 \%$ & $1.9 \%$ & $3.8 \%$ & $46.9 \%$ & $32.7 \%$ \\
\hline \multirow[t]{2}{*}{ 10-14 } & 33 & 3 & 3 & 1 & 2 & 0 & 1 & 3 & 3 & 2 & 1 & 17 & 12 \\
\hline & & $9.1 \%$ & $9.1 \%$ & $3.0 \%$ & $6.1 \%$ & $0 \%$ & $3.0 \%$ & $9.1 \%$ & $9.1 \%$ & $6.1 \%$ & $3.0 \%$ & $51.5 \%$ & $36.4 \%$ \\
\hline \multirow[t]{2}{*}{$\geq 15$} & 42 & 1 & 13 & 1 & 2 & 4 & 4 & 0 & 2 & 0 & 4 & 16 & 23 \\
\hline & & $2.4 \%$ & $31.0 \%$ & $2.4 \%$ & $4.8 \%$ & $11.4 \%$ & $9.5 \%$ & $0 \%$ & $4.8 \%$ & $0.0 \%$ & $9.5 \%$ & $38.1 \%$ & $54.8 \%$ \\
\hline \multirow[t]{2}{*}{ All } & 217 & 12 & 34 & 9 & 16 & 11 & 14 & 7 & 12 & 8 & 15 & 96 & 91 \\
\hline & & $5.5 \%$ & $15.7 \%$ & $4.2 \%$ & $7.4 \%$ & $7.4 \%$ & $6.5 \%$ & $3.2 \%$ & $5.5 \%$ & $3.7 \%$ & $6.9 \%$ & $44.2 \%$ & $41.9 \%$ \\
\hline
\end{tabular}

\footnotetext{
* Upper value indicates number of responders: lower value indicates percentage of responders. PPD = purified protein derivative of Mycobacterium bovis.
} 
TRAP peptide response $(34.6 \%, 36 / 104)$ compared with those without parasitemia $(48.7 \%, 55$ of 113$)(P=0.04)$. The precursor frequencies for all positive ELISPOT responses ( $\geq 13 / 10^{6}$ PBMCs) ranged from 13 to 100 , with a median of $22.5 / 10^{6}$ PBMCs, i.e., a median precursor frequency of $1: 44,444$, with a maximum of 1:10,000 (Table 3). These values are comparable with those in our previous study in The Gambia. ${ }^{10}$

$\mathrm{T}$ cell reactivity to CS protein, another major pre-erythrocytic vaccine candidate antigen, is focused on several epitope regions within the carboxy terminus of the antigen. ${ }^{31}$ Our previous studies of TRAP ELISPOT responses indicate no such pattern of immunodominance. ${ }^{10}$ This is further supported by the findings in this study where no clear immunodominant peptide region was evident. The high reactivity rate to pooled peptides tp4-6 (15.7\% of donors) is less striking if one considers the number of peptides in the pool. Thus, the most frequently recognized individual TRAP peptides were tp23 (7.4\% of donors) and tp51 (6.9\% of donors) (Table 2$)$. Both tp23 and tp51 are conserved among African parasite strains, and the former is highly conserved worldwide. Both could therefore elicit cross-strain immunity as components of malaria vaccine constructs. Forty-four percent (96 of 217) of the donors responded to PPD, whereas in previous IFN- $\gamma$ ELISPOT studies we have detected rates $>70 \%$ in malariaexposed Gambians. ${ }^{10,11}$

Similarities in reactivity between adults and children. A higher proportion of adults $(54.8 \%, 23$ of 42$)$ responded to at least one TRAP condition compared with children $(38.9 \%, 68$ of 175), although the difference was not statistically significant $(P=0.08)$. Those individuals less than one year of age had a low reactivity level of $28.6 \%(n=7)$ compared with the overall average of $42.4 \%(n=217)$, with no evidence of a significant difference $(P=0.73)$, although numbers were small in the former group (Figure 1A). The youngest donor to give an IFN- $\gamma$ ELISPOT assay response in this study was two months of age. Precursor frequencies for the positive re-

TABLE 3

Typical interferon- $\gamma$ enzyme-linked immunospot values for 20 of the 217 donors recruited to the study

\begin{tabular}{rrrrrrrrrrrr}
\hline Bg & tp2 & tp4-6 & tp14 & tp23 & tp30-1 & tp37/8 & tp40 & tp43 & tp47 & tp51 & PPD \\
\hline 3 & 3 & $\mathbf{2 3}$ & 5 & 5 & ND & 0 & 8 & 3 & 5 & 10 & 13 \\
5 & 3 & 8 & 5 & 3 & 5 & 5 & 5 & 5 & 0 & 0 & 3 \\
3 & 3 & $\mathbf{3 8}$ & 13 & 13 & 8 & 15 & 3 & 15 & 0 & 10 & $\mathbf{8 8}$ \\
0 & 8 & 3 & 3 & 8 & ND & 3 & 3 & 5 & 3 & $\mathbf{2 0}$ & 10 \\
0 & 3 & 0 & 0 & 5 & 3 & $\mathbf{1 8}$ & 3 & 0 & 3 & 3 & 0 \\
5 & 13 & 15 & 0 & 5 & 8 & 15 & 8 & 15 & 8 & 3 & $\mathbf{2 5}$ \\
3 & $\mathbf{1 8}$ & 3 & 0 & 0 & 10 & 0 & 8 & 3 & 8 & $\mathbf{1 8}$ & $\mathbf{3 3}$ \\
5 & 15 & 10 & 8 & 5 & 13 & 13 & 18 & 3 & 8 & 8 & 18 \\
0 & 8 & $\mathbf{2 3}$ & 3 & 8 & 5 & 10 & 8 & 10 & 10 & 10 & $\mathbf{3 8}$ \\
5 & 10 & $\mathbf{5 8}$ & 18 & 3 & 5 & 5 & 15 & 10 & 18 & 20 & $\mathbf{3 5}$ \\
0 & 3 & 0 & 0 & 0 & 0 & 3 & 0 & 3 & 0 & 10 & $\mathbf{2 3}$ \\
3 & 15 & 15 & 8 & 0 & 3 & 0 & 5 & 3 & 5 & $\mathbf{1 8}$ & $\mathbf{2 0}$ \\
5 & 15 & $\mathbf{3 0}$ & 8 & 20 & 13 & $\mathbf{7 3}$ & 5 & 18 & 13 & 0 & $\mathbf{2 3}$ \\
3 & 13 & 8 & 5 & 5 & 15 & 10 & 10 & 5 & 8 & 10 & $\mathbf{1 1 5}$ \\
5 & 3 & 10 & 0 & 15 & 13 & $\mathbf{2 5}$ & 15 & 5 & 3 & 8 & $\mathbf{7 0}$ \\
0 & 5 & 5 & $\mathbf{2 3}$ & 0 & 10 & $\mathbf{1 3}$ & 8 & 3 & 5 & 5 & $\mathbf{2 0}$ \\
3 & 3 & 13 & $\mathbf{1 8}$ & 5 & ND & 13 & 5 & 10 & 15 & 15 & 5 \\
0 & 10 & $\mathbf{2 8}$ & 10 & $\mathbf{1 3}$ & ND & 8 & 0 & 3 & 5 & 10 & $\mathbf{1 5}$ \\
8 & 18 & 18 & 18 & $\mathbf{2 8}$ & ND & 8 & 23 & 8 & 8 & 23 & 10 \\
3 & 10 & 20 & 15 & $\mathbf{2 3}$ & 10 & 10 & 5 & 15 & 10 & 10 & 13 \\
\hline$*$ & Positive & responses are indicated in bold. Bg $=$ background value; PPD $=$ purified \\
protein derivative of Mycobacterium tuberculosis. & & & & &
\end{tabular}

A.

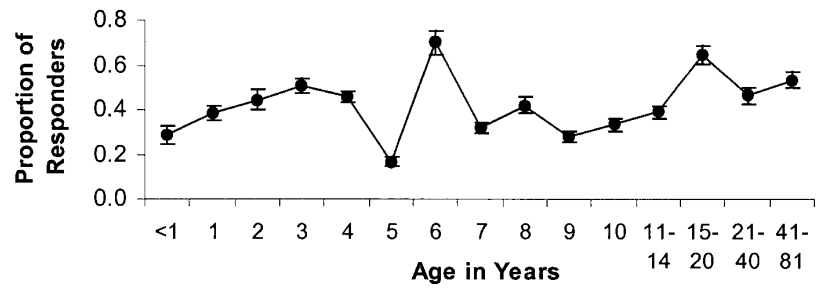

B.

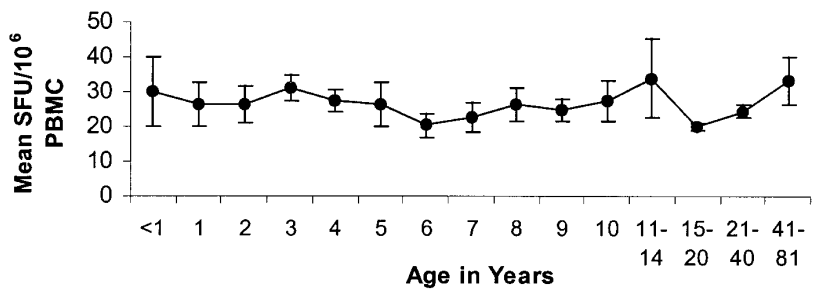

C.

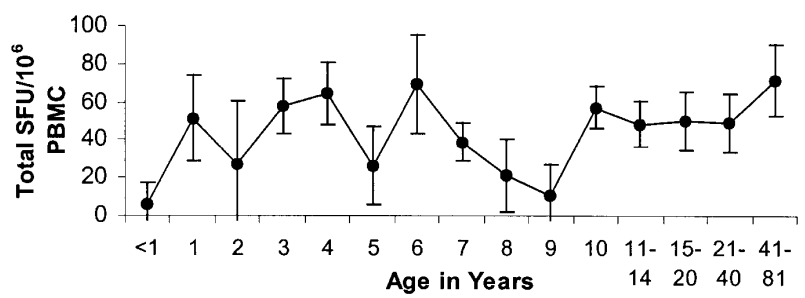

Figure 1. A, Proportion of responders to thrombospondinrelated adhesive protein (TRAP). An average of $42 \%$ of the donors responded to one or more TRAP peptides, and the numbers of responders were comparable across all age groups. B, Mean spotforming units (SFU) for positive TRAP responses (mean SFU/10 ${ }^{6}$ peripheral blood mononuclear cells [PBMC]) were comparable across all ages. C, Sums of the SFU to all 10 peptide conditions minus the background value (total SFU/10 $10^{6} \mathrm{PMC}$ ) were variable with age, with notable decreases at $<1$ and 9 years of age. Bars show $95 \%$ confidence intervals in $\mathbf{A}$ and the mean $\pm \mathrm{SE}$ in $\mathbf{B}$ and $\mathbf{C}$.

sponses were comparable across all age group (adults: median $=20$, range $=3-73$; children: median $=22.5$, range $=$ 13-100; $P=0.53$ ), and even those individuals less than one year of age showed a median precursor frequency of $30 \mathrm{SFU} /$ $10^{6}$ PBMCs, albeit in very few donors (Figure 1B). Selecting only positive responses introduces a selection bias since only those responses that reach a certain threshold above background levels are included (see Materials and Methods). Thus, the total precursor frequency to all 10 TRAP conditions (Total SFU) was also analyzed (Figure 1C). There was no evidence of an increase in total SFU with age $(P=0.3)$. Indeed, adults and children had comparable median total SFU values of 53 and 40 SFU/10 ${ }^{6}$ PBMCs, respectively, although those individuals less than one year of age did have a significantly lower value of $10 / 10^{6}$ PBMCs (SE = 12) compared with all other age groups $(P=0.01)$ (Figure $1 C)$. Thus, despite continuous and repeated exposure throughout life, neither the proportion of responders nor the precursor frequencies for TRAP specific responses increased with age after the age of one year.

We further analyzed the repertoire of epitope responses by 
age. Peptide tp4-6 was the most commonly recognized condition in most age groups (Table 2), which is not surprising given that this is the only condition consisting of three peptides. Thus, for those conditions consisting of more than one peptide, the responder number was divided by the number of peptides in the pool, i.e., divided by three for tp4-6 and two for tp30-31 and tp37-38. Peptides tp23 and tp51 thus emerged as the most commonly positive peptides in most age groups, although tp4-6 was the most commonly recognized in adults (Table 2). Peptide tp30-31 was the least commonly recognized overall. Thus, the repertoire of ELISPOT assay responses did not vary dramatically by age in this study.

Lack of an association between naturally induced levels of IFN- $\boldsymbol{\gamma}$ responses to TRAP and protection against malaria. All donors seen less than 20 times during the first 27 weeks of follow-up were excluded from the study; thus, 204 (94\%) of the donors were analyzed. The analysis of time to first episode was censored at eight months, during which time $51 \%$ of donors had one or more episodes of fever and parasitemia and $28 \%$ had one or more episodes of fever and $>10^{4}$ parasites/ $\mu \mathrm{L}$. Donors who responded to peptides tp14 and tp47 had a significantly decreased time to parasitemia $(P=0.05$ and 0.01 , respectively). However, this result should be interpreted with caution since analysis was univariate, was not adjusted for the effect of the other tp responses, and multiple analyses were performed, which increase the chance of a false-positive result. Indeed, the effect was not apparent when only donors with $>10^{4}$ parasites/ $\mu \mathrm{L}$ were considered. Each of the 10 TRAP conditions were analyzed individually for an association with protection against the subsequent development of parasitemia, and there was no evidence that any protected against the development of fever and parasitemia (any or $>10^{4} / \mu \mathrm{L}$ ) over the ensuing two months (10 weeks) or six months (27 weeks).

Those who responded in the IFN- $\gamma$ ELISPOT assay to one or more of the TRAP peptide conditions were compared with those who failed to respond. The TRAP peptide responders were not significantly protected against subsequent episodes of fever together with parasitemia (any and $>10^{4} / \mu \mathrm{L}$ over a two- and six-month period) compared with the nonresponders. Maentel-Haenzel tests for homogeneity suggested that there was no evidence for significantly different effects of tp responses on the likelihood of a subsequent episode between the different age categories (Table 4). The TRAP responders did not seem to progress more slowly to parasitemia (any or $>10^{4} / \mu \mathrm{L}$ ) than non-responders (Figure 2 ), and this was further confirmed by log-rank analysis ( $P$ values $=0.28-0.89$ ).

The responses to all 10 ELISPOT conditions were added together after subtracting the background value to derive a total precursor frequency to all 14 TRAP peptides and de- noted the total SFU. Total SFU values were normally distributed with a mean value of $45 / 10^{6}$ PBMCs and a standard deviation of 67.6 / $10^{6}$ PBMCs (Figure 3A), a negative value being derived when the background response was greater than the peptide-specific responses. Thus, the maximum precursor frequency to the 14 peptides tested in this study was 255 specific cells $/ 10^{6}$ PBMCs or one in every 4,000 PBMCs. A plot of total SFU by age as a continuous variable did not show any clear association. We hypothesized that those donors with higher total SFU values might be protected against episodes of fever and parasitemia. However there was no significant difference in total SFU values between those donors who developed fever and parasitemia and those who did not over a two-month $(P=0.11)$ or six-month period $(P=0.57)$ (Table $5)$. Further analysis for fever with a parasitemia $>10^{4} / \mu \mathrm{L}$ failed to show a significant effect over two $(P=0.78)$ and six months $(P=0.69)$ of follow-up (Table 5). Adjustments for age did not affect the results of this analysis.

Total SFU values were divided into four groups for further analysis: $<0,0-49,50-99$, and $\geq 100$. The proportion who have had at least one episode was estimated by time for each group for episodes of fever and any parasitemia or a parasitemia $>10^{4} / \mu \mathrm{L}$ ) (Figure $3 \mathrm{~B}$ and $\mathrm{C}$ ). The effect of total SFU category was estimated, adjusting for age, using Cox's proportional hazards. There was no evidence of a protective effect of total SFU (any parasitemia, $P=0.32$; parasitaemia $\left.<10^{4} / \mu \mathrm{L}, P=0.26\right)$.

Complete change in ELISPOT assay reactivity after one year. Adults and children showed similar reactivity in this study, suggesting that ex vivo ELISPOT assay responses might reflect recent exposure rather than long-term malaria experience. To assess whether ELISPOT assay reactivity changes over time, we retested 69 of the original 217 donors after one year in identical IFN- $\gamma$ ELISPOT assays using exactly the same assay conditions. The response rate in the retested donors was $36.2 \%$ ( 25 of 69 ), which was much lower than the response rate of $69.6 \%$ (48 of 69 ) the previous year. This may be due to selection bias since the retested donors were specifically selected because they responded in 1998. Indeed, the overall response rate in that year was $41.9 \%$ (91 of 217) for all donors tested, and thus comparable to the 1999 value of $36.8 \%(P=0.48)$. The PPD reactivity rates were low in $1998(40.6 \%)$ and 1999 (46.4\%), suggesting an overall low PPD reactivity in this population. The reason for this is not known. A PHA-positive control was included in the 1999 analysis and $100 \%$ of the donors gave a positive PHA response, indicating that a problem with the assay itself was not responsible for low reactivity. The precursor frequency values for 1998 and 1999 could not be compared because the background values were significantly higher on retesting in 1999.

Somewhat surprisingly, responses had entirely changed

TABLE 4

Analysis of those donors who had a thrombospondin-related adhesive protein peptide (tp) response compared to those who had none*

\begin{tabular}{|c|c|c|c|c|c|c|c|}
\hline & \multicolumn{3}{|c|}{ With a tp response } & \multicolumn{3}{|c|}{ Without a tp response } & \multirow[b]{2}{*}{$P$} \\
\hline & $\mathrm{n}$ & Frequency & $\%$ & $\mathrm{n}$ & Frequency & $\%$ & \\
\hline Any parasitemia in 2 months & 57 & 13 & 23 & 81 & 8 & 10 & 0.05 \\
\hline Parasitemia $>10^{4} / \mu \mathrm{L}$ in 2 months & 57 & 5 & 9 & 81 & 4 & 5 & 0.49 \\
\hline Any parasitemia in 6 months & 57 & 23 & 40 & 81 & 30 & 37 & 0.73 \\
\hline Parasitemia $>10^{4} / \mu \mathrm{L}$ in 6 months & 57 & 14 & 25 & 81 & 15 & 19 & 0.40 \\
\hline
\end{tabular}

* Frequency $=$ number of donors with at least one episode. The $P$ value in bold is statistically significant. 
A.

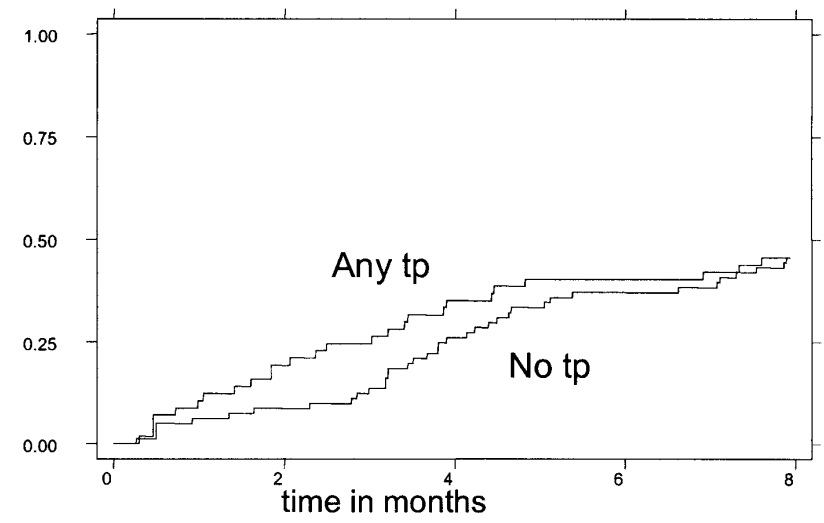

B.

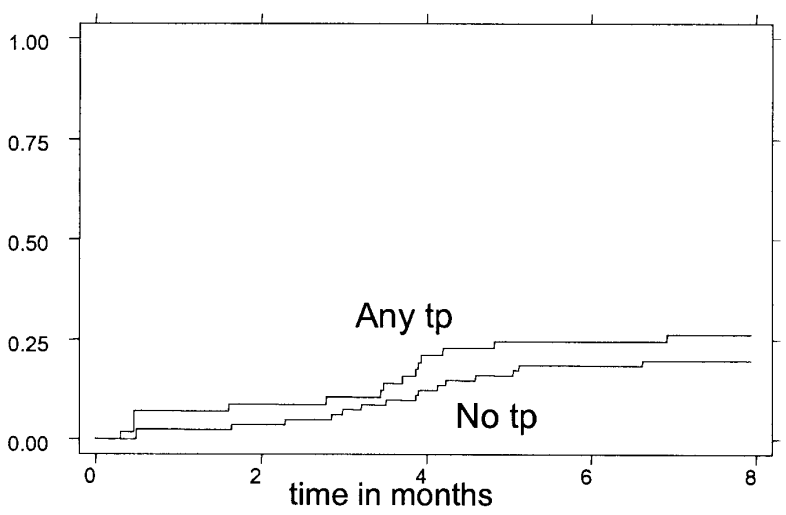

FIGURE 2. Kaplan-Meier plots of the proportion of donors having at least one episode by time for those donors who responded to one or more thrombospondin-related adhesive protein peptides (tps) (Any tp) compared with those who did not (No tp). Having a tp response failed to provide a significant survival advantage for the subsequent development of $\mathbf{A}$, any parasitemia or $\mathbf{B}$, a parasitemia $>10^{4} / \mu \mathrm{L}$.

over the one-year period, with only four $(5.3 \%)$ of the original 75 positive responses still present in 1999 (Table 6). There was no evidence of an association between those donors who responded to one or more TRAP condition in 1998 and those who responded in $1999(P=0.19)$. Our data suggests that malaria-specific reactivity detected by IFN- $\gamma$ ELISPOT assay is not long lasting in a malaria-exposed population, and may provide one explanation why the IFN- $\gamma$ ELISPOT assay responses failed to correlate with protection in this study.

The reactivity pattern to the 10 peptide conditions completely changed over the year in these 69 donors. Peptide tp23 was the most frequently recognized epitope on testing in 1998 (14 of 69 donors, $20.3 \%$ ) followed by tp51 (10 of 69 donors, $14.5 \%)$. However, one year later tp2 was most commonly recognized ( 9 of 69 donors, 13\%), followed by tp40 and tp47 ( 5 of 69 donors, $7.2 \%$ ). Both tp23 and tp2 fall within highly conserved regions of TRAP, suggesting a recognition bias for conserved epitopes. Indeed, the second most commonly recognized peptides (tp51 and tp40) are conserved in Africa, and tp47 has one polymorphic residue, but is conserved across almost all known strains of TRAP. ${ }^{32}$ A recognition bias for conserved regions of key parasite antigens obviates the host problems associated with antigenic polymorphism.

\section{DISCUSSION}

Residents of malaria-endemic regions acquire partial resistance to malaria infection, thus providing the rationale for studies of immunologic correlates of protection. Field studies assessing for protective $\mathrm{T}$ cell responses in malaria-exposed populations have generally used lymphoproliferation assays and assayed cytokine release by ELISA. ${ }^{1-6}$ The ELISPOT assay has been used to accurately determine malaria-specific $\mathrm{CD}^{+}$and $\mathrm{CD}^{+} \mathrm{T}$ cell precursor frequencies in naturally exposed and vaccinated individuals. ${ }^{10,11,13,16,33-35}$ However, no studies have addressed whether ELISPOT assay responses provide a surrogate of protective immunity. In the present study, we assessed 217 Kenyans by ELISPOT assay for rapid IFN- $\gamma$ release to 14 peptides spanning $42 \%$ of the malaria vaccine candidate antigen $P$. falciparum TRAP. Almost half $(42 \%)$ of the donors responded to one or more peptides, which included five novel epitopes, two of which are conserved in Africa.

Malaria mortality is mainly restricted to children in malaria-endemic regions. Thus, detailed comparison of reactivity between age groups provides useful information regarding the prevalence of ELISPOT assay responses throughout life. The proportion of TRAP-specific responders was comparable between children and adults, as were precursor frequency levels and the repertoire or responses. This contrasts with the findings of other investigators, who showed that malariaspecific IFN- $\gamma$ reactivity increases with age, ${ }^{34,36-38}$ albeit to other antigens. These latter studies assessed IFN- $\gamma$ reactivity by ELISA of cultured PBMCs. However, we know from previous studies that cultured cells do not give the same IFN- $\gamma$ ELISPOT assay reactivity as freshly isolated PBMCs. ${ }^{11} \mathrm{Re}-$ sponses were found from two months of age, which is the youngest age that malaria-specific ELISPOT assay responses have been shown.

Donors were followed up weekly for one year for the development of fever and parasitemia and analyzed for protective correlates with the IFN- $\gamma$ ELISPOT assay responses. This is the first study to assess for protective correlates with naturally induced $\mathrm{T}$ cell responses determined by ELISPOT assay, and also the first study of the protective efficacy of $\mathrm{T}$ cell responses to TRAP. A comprehensive analysis of time to first parasitemia and episodes of parasitemia two and six months after testing with the ELISPOT assay failed to show evidence of a protective association for any of the individual TRAP peptides. Indeed, having an IFN- $\gamma$ ELISPOT assay response to one or more of the TRAP peptides did not confer a protective advantage compared with the non-responders in this study. There was also no evidence of a protective effect for those donors with higher total precursor frequency levels to all 14 TRAP peptides (total SFU).

The presence of reactivity to multiple $\mathrm{T}$ cell determinants within TRAP in naturally exposed donors, ${ }^{10,25-27}$ and the pivotal role that TRAP and ex vivo IFN- $\gamma$ have shown in liverstage protective immunity in laboratory-based studies, ${ }^{7-9}$ suggested that high level $\mathrm{T}$ cell responses to TRAP would protect in studies of natural immunity. The lack of any evidence of a protective response using the predetermined endpoints (time 
A.

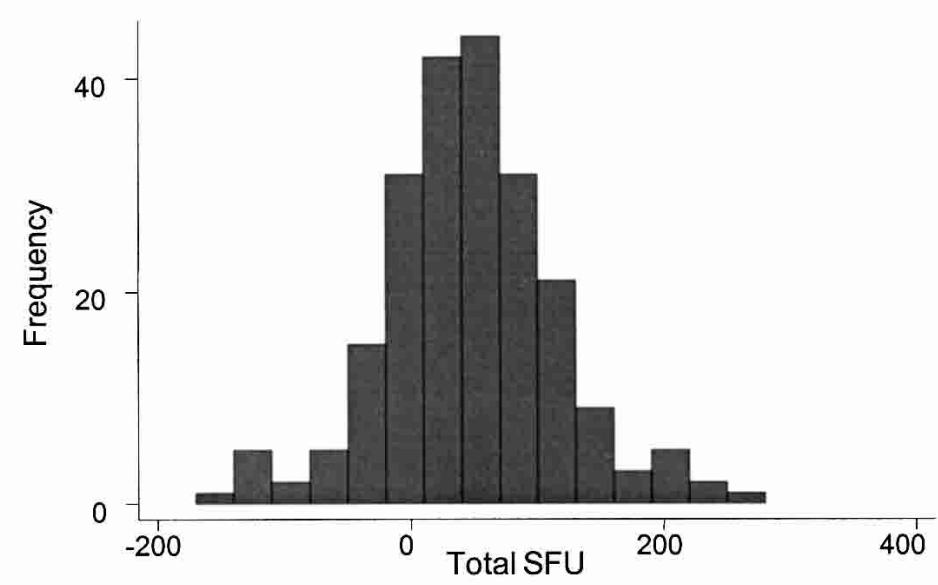

B.

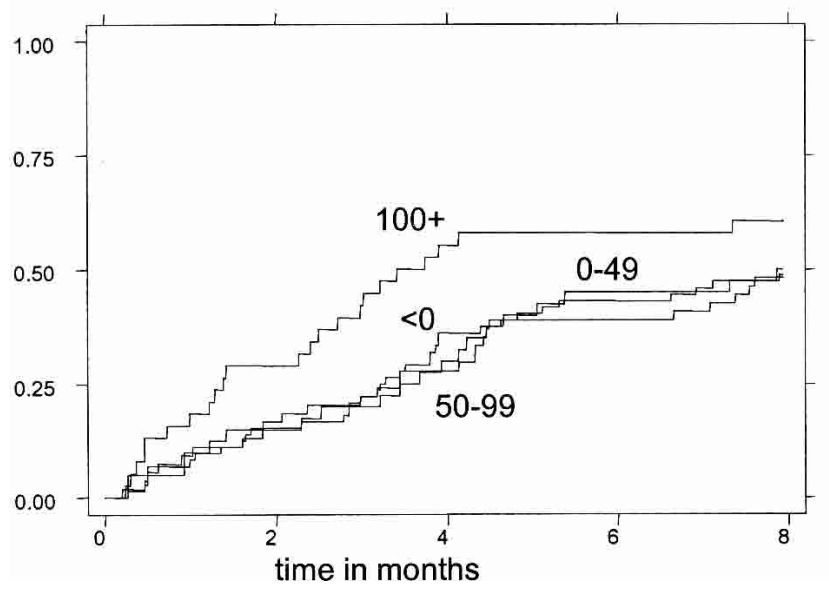

C.

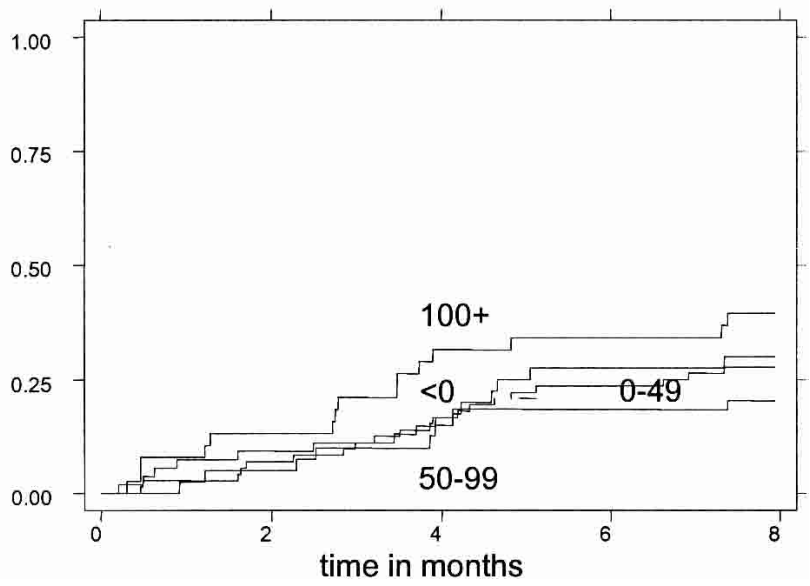

FIGURE 3. Sum of the enzyme-linked immunospot values to all 10 peptide conditions calculated for each donor (total spot-forming units [SFU]). A, The total SFU distribution for all 217 donors recruited into the study was normally distributed. Donors were separated into four categories according to their total SFU values $(<0,0-49,50-99$, and $\geq 100)$. Kaplan-Meier estimates of the four groups demonstrated that there was no significant survival advantage for donors with a high total SFU value and the subsequent development of an episode of fever and $\mathbf{B}$, any parasitemia or $\mathbf{C}$, a parasitemia $>10^{4} / \mu \mathrm{L}$.

to first episode of fever and parasitemia, development of parasitemia at different thresholds, and testing of conserved and variable epitope regions containing both CD4 and CD8 T cell epitopes) therefore deserves detailed consideration. The power of this study was determined retrospectively, since it was unknown at the onset how many donors would respond or the magnitude of the differences between groups. The best power achieved was $>46 \%$ for the any tp response versus no response analysis to detect a difference of $23 \%$ and $10 \%$ as significant. Increasing the number of donors would have in-

TABLE 5

Total spot-forming unit values and protection against malaria

\begin{tabular}{lcccccc}
\hline & \multicolumn{3}{c}{ One or more episodes } & & \multicolumn{3}{c}{ No episodes } \\
\cline { 2 - 4 } & $\mathrm{n}$ & Mean & $\mathrm{SE}$ & $\mathrm{n}$ & Mean & $\mathrm{SE}$ \\
\hline Any parasitemia in 2 months & 43 & 60.5 & 12.3 & 161 & 41.8 & 5.0 \\
Parasitemia $>10^{4} / \mu \mathrm{L}$ in 2 months & 19 & 49.9 & 20.6 & 185 & 45.3 & 0.11 \\
Any parasitemia in 6 months & 92 & 48.7 & 8.0 & 112 & 43.3 & 5.8 \\
Parasitemia $>10^{4} / \mu \mathrm{L}$ in 6 months & 51 & 49.0 & 11.1 & 153 & 44.7 & 0.78 \\
\hline
\end{tabular}


TABLE 6

Representative results for 20 of the 69 donors re-tested in 1999*

1998

$\begin{array}{llllllllll}2 & 4-6 & 14 & 23 & 30-1 & 37-8 & 40 & 43 & 47 & 51\end{array}$
1999

$\begin{array}{llllllllll}2 & 4-6 & 14 & 23 & 30-1 & 37-8 & 40 & 43 & 47 & 51\end{array}$

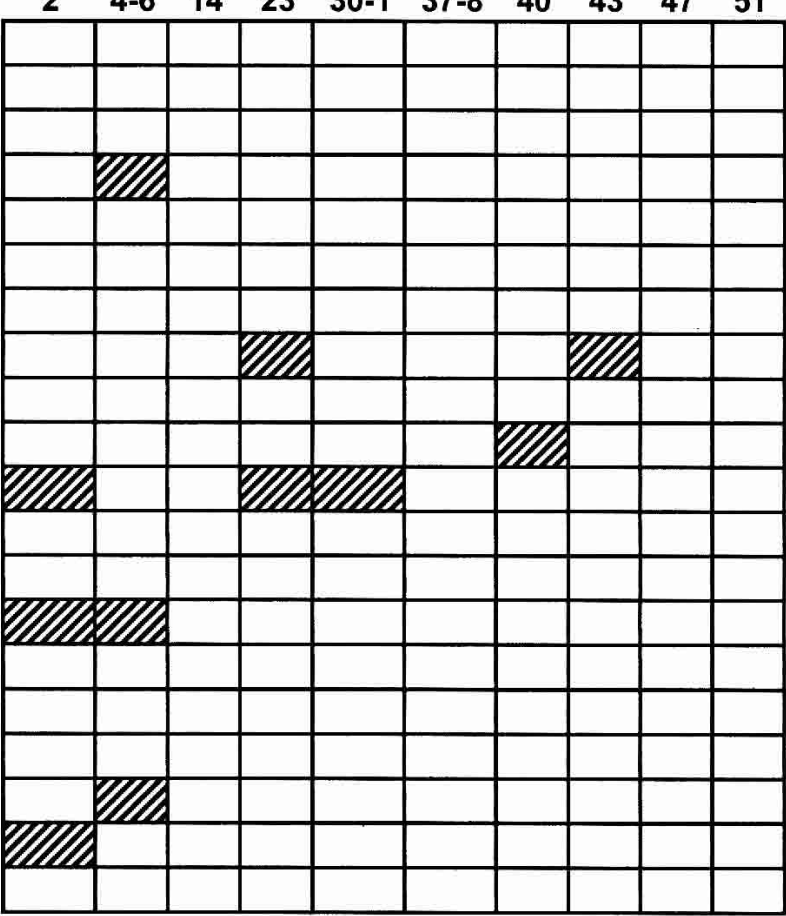

* Filled or hatched boxes indicate a positive response.

creased the power of this study. However, it was notable that none of the parameters analyzed suggested a protective effect.

The ex vivo IFN- $\gamma$ ELISPOT assay is frequently used to assess for $\mathrm{T}$ cell responses in studies of malaria vaccine efficacy in humans. ${ }^{16,35}$ It is therefore important to test whether IFN- $\gamma$ ELISPOT assay responses measured in field studies are indeed protective. The only study linking IFN- $\gamma$ responses in naturally exposed individuals with protection against malaria infection used PBMCs cultured for six days with peptides derived from the liver stage antigen-1, i.e., a cultured rather than an ex vivo assay. ${ }^{5}$ Freshly isolated ex vivo PBMCs do not respond to the same malaria peptides in the IFN- $\gamma$ ELISPOT assay as PBMCs cultured for 14 days in peptides, suggesting that the two methods detect different $\mathrm{T}$ cell subsets. ${ }^{11}$ Thus, the ELISPOT assay of cultured cells may detect protective $\mathrm{T}$ cells not apparent in the ex vivo assay. It is not clear how long IFN- $\gamma$ ELISPOT assay responses are maintained in naturally exposed donors, but in an RTS,S vaccine trial malaria, specific $\mathrm{T}$ cell responses measured by an ex vivo ELISPOT assay waned after one month. ${ }^{39}$ The temporal variation of malaria-specific ELISPOT assay responses have yet to be assessed in the field, but might be predicted to alter according to seasonality as observed with other measures of $\mathrm{T}$ cell function. ${ }^{40-42}$ In the present study, repeat testing after one year for selected donors demonstrated completely changed reactivities for all donors, suggesting that responses do not persist long-term and might reflect recent malaria exposure. Indeed, the parasitemic donors in 1998 were more likely to be TRAP non-responders than aparasitemic. Thus, ongoing malaria infection at the time of testing may suppress malaria-specific ELISPOT assay reactivity, a phenomenon well described for malaria-specific lymphoproliferative responses. ${ }^{43-45}$ We did not allow for an absence of parasitemia at the time of testing in the analysis for this study.

It is possible that $\mathrm{T}$ cell responses to TRAP are not protective. One would think that this unlikely given the role of TRAP in sporozoite motility ${ }^{20}$ and hepatocyte invasion. ${ }^{21}$ Moreover, TRAP homologues have repeatedly been shown to be protective in animal models, ${ }^{14,22-24}$ although the ELISPOT assay reactivity for a single epitope reached 1,000 specific cells $/ 10^{6}$ splenocytes in protected animals in the latter study. ${ }^{24}$ In our study, the maximum precursor frequency to all 14 epitopes was $255 / 10^{6} \mathrm{PBMCs}$ (median $=43 / 10^{6} \mathrm{PBMCs}$ ) or one in 4,000. However, we do not know how numbers of specific splenic cells correlate with specific PBMCs. Most of the peptides used in this study elicited $\mathrm{CD} 4^{+} \mathrm{T}$ cell responses, and only peptide pool tp4- 6 contained proven $\mathrm{CD}^{+} \mathrm{T}$ cell epitopes. TRAP-specific $\mathrm{CD}^{+} \mathrm{T}$ cells and/or antibodies may be protective in this population, rather than $\mathrm{CD}^{+} \mathrm{T}$ cells. Certainly, field studies suggest that antibodies to TRAP play a protective role, ${ }^{28,29}$ but no studies have previously directly addressed the role of TRAP-specific T cells in naturally induced protection. Several studies have correlated protection with interleulin-4 (IL-4) or IL-10 release in response to various vaccine candidate antigens, ${ }^{3,4}$ and the profile of other cytokines induced by TRAP may have influenced our results. Indeed, in a separate study, we found high levels of IL-10 
reactivity to the same TRAP-derived peptides in coastal Kenyans (Flanagan KL and others, unpublished data).

This study provides evidence that the levels of epitopespecific $\mathrm{T}$ cell responses (median $=23 / 10^{6} \mathrm{PBMCs}$ ) in individuals with significant natural exposure to malaria do not afford detectable protection against malaria infection. This is consistent with studies of animal models of malaria that indicate that immune responses approximately an order of magnitude higher than this are required to induce protection against sporozoite challenge. Thus, it is likely that similarly high levels of $\mathrm{T}$ cell response will need to be induced by subunit vaccination in humans to afford useful protection. Recent data from Phase I/IIa studies of heterologous primeboost immunization with DNA and modified virus Ankara (MVA) vaccines encoding TRAP are consistent with this interpretation (McConkey SJ and others, unpublished data).

Studies for protective $\mathrm{T}$ cell responses in malaria-endemic regions are crucial to the development of effective malaria vaccines. This comprehensive study of more than 200 naturally exposed donors provides useful information regarding ELISPOT assay reactivity in naturally exposed populations, and provides baseline data for ongoing field efficacy trials of TRAP-based candidate vaccines.

Received September 30, 2002. Accepted for publication December 26, 2002.

Acknowledgments: We thank the residents of Ngerenya for participating in this study, and all the field staff involved in the longitudinal follow-up. Katie L. Flanagan was funded by a Wellcome Trust Clinical Tropical Training Fellowship. Magdalena Plebanski is a Howard Hughes Scholar. Adrian V. S. Hill and Kevin Marsh are Wellcome Trust Principal Fellows.

Authors' addresses: Katie L. Flanagan, Northwick Park Hospital, Watford Road, Harrow, Middlesex HA1 3UJ, United Kingdom, Telephone: 44-208-864-3232, Fax: 44-208-869-2009, E-mail: katie.flanagan@lshtm.ac.uk. Tabitha Mwangi, Kennedy Odhiambo, Amanda Ross, Moses Kortok, Brett Lowe, and Kevin Marsh, KEMRI-Centre for Geographic Medicine-Coast, PO Box 230, Kilifi, Kenya. Magdalena Plebanski, Vaccine Development and Infectious Diseases Unit, The Austin Research Institute, The Austin and Repatriation Medical Centre, Studley Road, Heildelberg, Victoria 3084, Australia. Eric Sheu and Adrian V. S. Hill, Weatherall Institute of Molecular Medicine, University of Oxford, John Radcliffe Hospital, Headington, Oxford OX3 9DS, United Kingdom.

\section{REFERENCES}

1. Hoffman SL, Oster CN, Mason C, Beier JC, Sherwood JA, Ballou WR, Mugambi M, Chulay JD, 1989. Human lymphocyte proliferative response to a sporozoite $\mathrm{T}$ cell epitope correlates with resistance to falciparum malaria. J Immunol 142: 12991303.

2. Riley EM, Allen SJ, Bennett S, Thomas PJ, O'Donnell A, Lindsay SW, Good MF, Greenwood BM, 1990. Recognition of dominant $\mathrm{T}$ cell-stimulating epitopes from the circumsporozoite protein of Plasmodium falciparum and relationship to malaria morbidity in Gambian children. Trans $R$ Soc Trop Med Hyg 84: 648-657.

3. Al-Yaman F, Genton B, Taraika J, Anders R, Alpers MP, 1997. Association between cellular response (IL-4) to RESA/Pf155 and protection from clinical malaria among Papua New Guinean children living in a malaria endemic area. Parasite Immunol 19: 249-254.

4. Kurtis JD, Lanar DE, Opollo M, Duffy PE, 1999. Interleukin-10 responses to liver-stage antigen 1 predict human resistance to Plasmodium falciparum. Infect Immun 67: 3424-3429.

5. Luty AJF, Lell B, Schmidt-Ott R, Lehman LG, Luckner D, Greve B, Matousek P, Herbich K, Schmid D, Migot-Nabias F,
Deloron P, Nussenzweig RS, Kremsner PG, 1999. Interferon- $\gamma$ responses are associated with resistance to reinfection with Plasmodium falciparum in young African children. J Infect Dis 179: 980-988.

6. Migot-Nabias F, Deloran P, Ringwald P, Dubois B, Mayombo J, Minh TN, Fievet N, Millet P, 2000. Immune response to Plasmodium falciparum liver stage antigen-1: geographical variations within Central Africa and their relationship with protection from clinical malaria. Trans $R$ Soc Trop Med Hyg 94: $557-562$.

7. Ferreira A, Schofield L, Enea V, Schellekens H, van der Meide P, Collins WE, Nussenzweig RS, Nussenzweig V, 1986. Inhibition of development of exoerythrocytic forms of malaria parasites by interferon-gamma. Science 232: 881-884.

8. Schofield L, Ferreira A, Altszuler R, Nussenzweig V, Nussenzweig RS, 1987. Interferon-gamma inhibits the intrahepatocytic development of malaria parasites in vitro. J Immunol 139: 2020-2025.

9. Mellouk S, Green S, Nacy C, Hoffman SL, 1991. IFN-gamma inhibits development of Plasmodium berghei exoerythrocytic stages in hepatocytes by an L-arginine-dependent effector mechanism. J Immunol 146: 3971-3976.

10. Flanagan KL, Plebanski M, Akinwunmi P, Lee EAM, Reece WHH, Robson KJH, Hill AVS, Pinder M, 1999. Broadly distributed T cell reactivity, with no immunodominant loci, to the pre-erythrocytic antigen thrmobospondin-related adhesive protein of Plasmodium falciparum in West Africans. Eur $J$ Immunol 29: 1943-1954.

11. Flanagan KL, Lee EAM, Gravenor MB, Reece WHH, Urban BC, Doherty T, Bojang KA, Pinder M, Hill AVS, Plebanski M, 2001. Unique T cell effector functions elicited by Plasmodium falciparum epitopes in malaria-exposed Africans tested by three T cell assays. J Immunol 167: 4729-4737.

12. Lee EAM, Flanagan KL, Odhiambo K, Reece WHH, Potter CG, Bailey R, Marsh K, Pinder M, Hill AVS, Plebanski M, 2001. Identification of frequently recognized dimorphic T-cell epitopes in Plasmodium falciparum merozoite surface protein-1 in West and East Africans: lack of correlation of immune recognition and allelic prevalence. Am J Trop Med Hyg 64: 194-203.

13. Reece WHH, Plebanski M, Akinwunmi P, Gothard P, Flanagan KL, Lee EAM, Cortina-Borja M, Hill AVS, Pinder M, 2002. Naturally exposed populations differ in their T1 and T2 responses to the circumsporozoite protein of Plasmodium falciparum. Infect Immun 70: 1468-1474.

14. Schneider J, Gilbert SC, Blanchard TJ, Hanke T, Robson KJH, Hannan CM, Becker M, Sinden R, Smith GL, Hill AVS, 1998. Enhanced immunogenicity for $\mathrm{CD}^{+} \mathrm{T}$ cell induction and complete protective efficacy of malaria DNA vaccination by boosting with modified vaccinia virus Ankara. Nat Med 4: 397-402.

15. Plebanski M, Gilbert SC, Schneider J, Hannan CM, Layton G, Blanchard T, Becker M, Smith G, Butcher G, Sinden RE, Hill AVS, 1998. Protection from Plasmodium berghei infection by priming and boosting $\mathrm{T}$ cells to a single class-I-restricted epitope with recombinant carriers suitable for human use. Eur J Immunol 28: 1-11.

16. Stoute JA, Slaoui M, Gray Heppner D, Momin P, Kester KE, Desmons P, Wellde BT, Garçon N, Krzych U, Marchand M, Ballou WR, Cohen JD, 1997. A preliminary evaluation of a recombinant circumsporozoite protein vaccine against Plasmodium falciparum malaria. $N$ Engl J Med 336: 86-91.

17. Robson KJH, Hall JRS, Jennings MW, Harris TJR, Marsh K, Newbold CI, Tate VE, Weatherall DJ, 1988. A highly conserved amino-acid sequence in thrombospondin, properdin and in proteins from sporozoites and blood stages of a human malaria parasite. Nature 355: 79-82.

18. Rogers WO, Malik A, Mellouk S, Nakamura K, Rogers MD, Szarfman A, Gordon DM, Nussler AK, Aikawa M, Hoffman SL, 1992. Characterization of Plasmodium falciparum sporozoite surface protein 2. Proc Natl Acad Sci USA 89: 9176-9180.

19. Gannt S, Persson C, Rose K, Birkett AJ, Abagyan R, Nussenzweig V, 2000. Antibodies against thrombospondin-related anonymous protein do not inhibit Plasmodium sporozoite infectivity in vivo. Infect Immun 68: 3667-3673.

20. Sultan AA, Thathy V, Frevert U, Robson KJH, Crisanti A, Nus- 
senzweig V, Nussenzwig RS, Menard R, 1997. TRAP is necessary for gliding motility and infectivity of sporozoites. Cell 90: $511-522$.

21. Müller H-M, Reckmann I, Hollingdale MR, Bujard H, Robson KJH, Crisanti A, 1993. Thrombospondin related anonymous protein (TRAP) of Plasmodium falciparum binds specifically to sulfated glycoconjugates and to HepG2 hepatoma cells suggesting a role for this molecule in sporozoite invasion of hepatocytes. EMBO J 12: 2881-2889.

22. Khusmith S, Sedegah M, Hoffman SL, 1994. Complete protection against Plasmodium yoelii by adoptive transfer of a $\mathrm{CD}^{+} \mathrm{cy}-$ totoxic T-cell clone recognizing the sporozoite surface protein 2. Infect Immun 62: 2979-2983.

23. Khusmith S, Charoenvit Y, Kumar S, Sedegah M, Beaudoin RL, Hoffman SL, 1991. Protection against malaria by vaccination with sporozoite surface protein 2 plus CS protein. Science 252: 715-718.

24. Wang R, Charoenvit Y, Corradin G, De La Vega P, Franke ED, Hoffman SL, 1996. Protection against malaria by Plasmodium yoelii sporozoite surface protein 2 linear peptide induction of CD4+ T cell- and IFN-gamma-dependent elimination of infected hepatocytes. J Immunol 157: 4061-4067.

25. Aidoo M, Lalvani A, Allsopp CEM, Plebanski M, Meisner SJ, Krausa P, Browning M, Morris-Jones S, Gotch F, Fidock DA, Takiguchi M, Robson KJH, Greenwood BM, Druihle P, Whittle HC, Hill AVS, 1995. Identification of conserved antigenic components for a cytotoxic T lymphocyte-inducing vaccine against malaria. Lancet 345: 1003-1007.

26. Wizel B, Houghten RA, Church P, Tine JA, Lanar DE, Gordon DM, Ballou WR, Sette A, Hoffman SL, 1995. HLA-A2restricted cytotoxic T lymphocyte responses to multiple Plasmodium falciparum Sporozoite Surface Protein 2 epitopes in sporozoite-immunized volunteers. J Immunol 155: 766-775.

27. Doolan DL, Hoffman SL, Southwood S, Wentworth PA, Sidney J, Chesnut RW, Keogh E, Apella E, Nutman TB, Lal AA, Gordon DM, Oloo A, Sette A, 1997. Degenerate cytotoxic T cell epitopes from $P$. falciparum restricted by multiple HLA-A and HLA-B supertype alleles. Immunity 7: 97-112.

28. Scarselli E, Tölle R, Koita O, Diallo M, Müller H-M, Früh K, Doumbo O, Crisanti A, Bujard H, 1993. Analysis of the human antibody responses to thrombospondin-related anonymous protein of Plasmodium falciparum. Infect Immun 61: 34903495.

29. Dolo A, Modiano D, Doumbo O, Bosman A, Sidibe T, Keita MM, Naitza S, Robson KJ, Crisanti A, 1999. Thrombospondin related adhesive protein (TRAP), a potential malaria vaccine candidate. Parassitologia 41: 425-428.

30. Mbogo CN, Snow RW, Khamala CP, Kabiru EW, Ouma JH, Githure JI, Marsh K, Beier JC, 1995. Relationship between Plasmodium falciparum transmission by vector populations and the incidence of severe disease at nine sites on the Kenyan coast. Am J Trop Med Hyg 52: 201-206.

31. Good MF, Pombo D, Quakyi IA, Riley EM, Houghten RA, Menon A, Alling DW, Berzofsky JA, Miller LH, 1988. Human T-cell recognition of the circumsporozoite protein of Plasmodium falciparum: immunodominant T-cell domains map to the polymorphic regions of the molecule. Proc Natl Acad Sci USA 85: 1199.

32. Robson KJH, Hall JRS, Davies LC, Crisanti A, Hill AVS, Wellems TE, 1990. Polymorphism of the TRAP gene of Plasmodium falciparum. Proc $R$ Soc Lond B Biol Sci 242: 205-216.

33. Bonelo A, Valmori D, Triponez F, Tiercy JM, Mentha G, Oberholzer J, Champagne P, Romero JF, Esposito F, Nebie I, Barbey C, Romero P, Herrera S, Corradin G, Lopez JA, 2000.
Generation and characterization of malaria-specific human CD8(+) lymphocyte clones: effect of natural polymorphism on $\mathrm{T}$ cell recognition and endogenous cognate antigen presentation by liver cells. Eur J Immunol 30: 3079-3088.

34. Bucci K, Kastens W, Hollingdale MR, Shanker A, Alpers MP, King CL, Kazura JW, 2000. Influence of age and HLA type on interferon-gamma (IFN- $\gamma$ ) responses to a naturally occurring polymorphic epitope of Plasmodium falciparum liver stage antigen-1 (LSA-1). Clin Exp Immunol 122: 94-100.

35. Wang R, Epstein J, Baraceros FM, Gorak EJ, Charoenvit Y, Carucci DJ, Hedstrom RC, Rahardjo N, Gay T, Hobart P, Stout R, Jones TR, Richie TL, Parker SE, Doolan DL, Norman J, Hoffman SL, 2001. Induction of CD4(+) T celldependent CD8(+) type 1 responses in humans by a malaria DNA vaccine. Proc Natl Acad Sci USA 98: 10817-10822.

36. Fievet N, Ringwald P, Bickii J, Dubois B, Maubert B, Le Hesran JY, Cot M, Deloran P, 1996. Malaria cellular immune responses in neonates from Cameroon. Parasite Immunol 18: 483-490.

37. Al-Yaman F, Genton B, Taraika J, Anders R, Alpers MP, 1997. Cellular immunity to merozoite surface protein 2 (FC27 and 3D7) in Papua New Guinean children. Temporal variation and relation to clinical and parasitological status. Parasite Immunol 19: $207-214$

38. John CC, Sumba PO, Ouma JH, Nahlen BL, King CL, Kazura JW, 2000. Cytokine responses to Plasmodium falciparum liverstage antigen 1 vary in rainy and dry seasons in highland Kenya. Infect Immun 68: 5198-5204.

39. Lalvani A, Moris P, Voss G, Pathan AA, Kester KE, Brookes R, Lee E, Koutsoukos M, Plebanski M, Delchambre M, Flanagan KL, Carton C, Slaoui M, van Hoecke C, Ballou WR, Hill AVS, Cohen J, 1999. Potent induction of focused Th1-type cellular and humoral immune responses by RTS,S/SBAS2, a recombinant Plasmodium falciparum malaria vaccine. J Infect Dis 180: 1656-1664.

40. Theander TG, Bygberg IC, Andersen BJ, Jepsen S, Kharazmi A, Ødum N, 1986. Suppression of parasite-specific response in Plasmodium falciparum malaria. A longitudinal study of blood mononuclear cell proliferation and subset composition. Scand J Immunol 24: 73-81.

41. Troye-Blomberg M, Riley EM, Perlmann H, Andersson G, Snow RW, Allen SJ, Houghten RA, Olerup O, Greenwood BM, Perlmann P, 1989. T- and B-cell responses of Plasmodium falciparum malaria-immune individuals to synthetic peptides corresponding to epitopes in the conserved repeat regions of the $P$. falciparum antigen Pf155/RESA. J Immunol 25: 1002-1008.

42. Riley EM, Morris-Jones S, Blackman MJ, Greenwood BM, Holder AA, 1993. A longitudinal study of naturally acquired cellular and humoral immune responses to a merozoite surface protein (MSP1) of Plasmodium falciparum in an area of seasonal malaria transmission. Parasite Immunol 15: 513-524.

43. Ho M, Webster HK, Looareesuwan S, Supanaranond W, Phillips RE, Chanthavanich P, Warrell DA, 1986. Antigen-specific immunosuppression in human malaria due to Plasmodium falciparum. J Infect Dis 153: 763-771.

44. Theander TG, Bygberg IC, Jacobsen L, Jepsen S, Larsen PB, Kharazmi A, 1986. Low parasite specific $\mathrm{T}$ cell response in clinically immune individuals with low grade Plasmodium falciparum parasitaemia. Trans $R$ Soc Trop Med Hyg 80: 10001001.

45. Hviid L, Theander TG, Abu Zeid YA, Abdulhadi NH, Jakobsen PH, Saeed BO, Jepsen S, Bayoumi RA, Jensen JB, 1991. Loss of cellular immune reactivity during acute Plasmodium falciparum malaria. FEMS Microbiol Immunol 3: 219-227. 